\title{
Bilateral retinal pathology following a first-ever clinical episode of autoimmune optic neuritis
}

Carla A. Wicki, MSc, Praveena Manogaran, MSc, Tanja Simic, RN, James V.M. Hanson, PhD, and Sven Schippling, MD

Neurol Neuroimmunol Neuroinflamm 2020;7:e671. doi:10.1212/NXI.0000000000000671

\section{Abstract}

\section{Objective}

This longitudinal study aimed to assess changes in retinal structure and visual function following a first-ever episode of acute optic neuritis $(\mathrm{ON})$.

\section{Methods}

Clinical and optical coherence tomography (OCT) data obtained over a period of 12 months were retrospectively analyzed in 41 patients with a first-ever clinical episode of acute ON. OCT scans, high-contrast visual acuity (HCVA), and low-contrast visual acuity (LCVA) were acquired at baseline and at 1, 3, 6, and 12 months thereafter. Macular ganglion cell and inner plexiform layer (GCIP), peripapillary retinal nerve fiber layer (pRNFL), and macular inner nuclear layer (INL) thicknesses were assessed by OCT. Linear mixed-effects models were used to analyze OCT variables of ipsilateral ON and contralateral non-ON (NON) eyes over time.

\section{Results}

The mean change of GCIP thickness in ON eyes was significant at all follow-up time points, with nearly $75 \%$ of the total reduction having occurred by month 1 . In ON eyes, thinner GCIP thickness at month 1 correlated with lower LCVA at month 3. Mean pRNFL thickness in ON eyes differed significantly from NON eyes at all postbaseline time points. INL thickness was significantly increased in ON eyes (month 1) but also in contralateral NON eyes (month 12).

\section{Conclusions}

Retinal structural damage develops rapidly following acute $\mathrm{ON}$ and is associated with subsequent functional visual deficits. Our results also suggest bilateral retinal pathology following unilateral ON, possibly caused by subclinical involvement of the contralateral NON eyes. Moreover, our data may assist in clinical trial planning in studies targeting tissue damage in acute $\mathrm{ON}$.

\author{
Correspondence \\ Carla A. Wicki \\ wickic@student.ethz.ch
}




\section{Glossary}

DMT = disease-modifying therapy; GCIP = ganglion cell and inner plexiform layer; HCVA = high-contrast visual acuity; INL = inner nuclear layer; LCVA = low-contrast visual acuity; $\operatorname{logMAR}=$ logarithm of the minimum angle of resolution; MME = microcystic macular edema; NMOSD = neuromyelitis optica spectrum disorder; NON = nonoptic neuritis; OCT = optical coherence tomography; $\mathbf{O N}$ = optic neuritis; $\mathbf{O N H}=$ optic nerve head; $\mathbf{p R N F L}=$ peripapillary retinal nerve fiber layer; $\mathbf{R G C}=$ retinal ganglion cell; VEP = visual evoked potential.

Optic neuritis $(\mathrm{ON})$ is an acute inflammation of the optic nerve and a frequent clinical manifestation of $\mathrm{MS}^{1-3}$ Within the retina, $\mathrm{ON}$-associated neuroaxonal damage manifests as peripapillary retinal nerve fiber layer ( $\mathrm{pRNFL}$ ) and macular ganglion cell layer thinning, which can be detected in vivo using optical coherence tomography (OCT).$^{4-7}$ Studies have found that $\mathrm{pRNFL}$ and the combined macular ganglion cell and inner plexiform layer (GCIP) thickness strongly correlated with functional visual outcomes in $\mathrm{ON}^{8,9}$ A multicenter study recently found that pRNFL thickness below a certain threshold was predictive of a more disabling disease course. ${ }^{10}$ In addition to the inner retina, changes to the outer retina (e.g., inner nuclear layer [INL]) have been observed after ON. ${ }^{11-13}$

Of interest, previous studies have found that the clinically unaffected contralateral eye may display some degree of dysfunction following unilateral ON. ${ }^{14-16}$ Structural data to date are only available for the outer retina over 6 months after $\mathrm{ON}^{17}$ or for the inner retina over 12 months. ${ }^{18}$ Although a number of cross-sectional OCT studies in ON have been published, ${ }^{8,19}$ longitudinal studies are still scarce. ${ }^{12,17,18}$

The primary goal of this study was to describe the temporal dynamics and magnitude of retinal structural and functional visual damage in patients with a first-ever $\mathrm{ON}$ in the affected and unaffected eyes. Further objectives included investigating the association between early macular damage and visual outcomes and exploratory analysis of sex-specific differences during $\mathrm{ON}$.

\section{Methods}

\section{Study design}

Forty-one patients with a first-ever acute $\mathrm{ON}$ were identified retrospectively by chart review, and their clinical and OCT data were analyzed longitudinally over a period of 12 months following the episode. Patient data were acquired at baseline (defined as symptom onset \pm 28 days maximum after onset of ON) and, relative to baseline, at 1 (24-38 days), 3 (79-107 days), 6 (158-214 days), and 12 (310-434 days) months thereafter between 2014 and 2017.

\section{Standard protocol approvals, registrations, and patient consents}

The study was approved by the Ethics Committee of the Canton of Zurich, Switzerland (reference KEK-ZH-Nr.20130001), and all patients signed a general informed consent form.

\section{Patients eligibility}

Patients with a first-ever episode of $\mathrm{ON}$, including idiopathic $\mathrm{ON}$ and $\mathrm{ON}$ in the context of MS (diagnosed according to the 2010 revised $\mathrm{McDonald}$ criteria $^{20}$ ), were included in the study. ON was diagnosed by experienced clinicians from the Departments of Neurology and Ophthalmology at the University Hospital Zurich, Switzerland. Patients were included if OCT and visual acuity assessments were performed at baseline and at least one more of the predefined time points. Exclusion criteria included previous clinical history of $\mathrm{ON}$ in either eye, retinal pathology (visible on ophthalmologic or OCT examination) or any other ocular or systemic disease, which could affect vision or retinal structure (e.g., diabetes mellitus and uncontrolled hypertension), refractive error $\geq 6.0$ diopters, and history of eye surgery.

\section{Visual acuity}

High-contrast visual acuity (HCVA) and low-contrast visual acuity (LCVA) were recorded at each visit with habitual refractive correction. HCVA was tested using Early Treatment Diabetic Retinopathy Study charts (100\% contrast), and LCVA was tested with Sloan letter charts ( $2.5 \%$ contrast). For both, the number of correctly identified letters was recorded and specified with the logarithm of the minimum angle of resolution (logMAR) scale. ${ }^{21}$

\section{Optical coherence tomography}

OCT was performed using a single Heidelberg Spectralis OCT device (Software version 1.9.10.0; Heidelberg Engineering, Heidelberg, Germany) by 3 experienced OCT operators. The device is equipped with a TruTrack eye tracking program. OCTs were performed without pupillary dilation in a darkened room. Scans were acquired at baseline and at 1, 3, 6, and 12 months after ON. The macular volume protocol was performed in high-resolution mode and involved 19 consecutive vertical B scans (25 automatic real-time tracking, 1,536 A-scans per B scan, $240 \mu \mathrm{m}$ between B scans) crossing the macula using an integrated macular volume protocol ("PPoleV"). The pRNFL thickness protocol involved a high-resolution peripapillary ring scan $\left(12^{\circ}\right.$ diameter, 30 automatic real-time tracking) centered over the optic nerve head (ONH). For postprocessing, retinal layer segmentation was performed automatically using the built-in Heidelberg retina angiograph/ Spectralis Viewer Module (v.6.3.4.0). The mean thickness of the macular ganglion cell layer, inner plexiform layer, and INL was calculated by centering the $1.00-\mathrm{mm}, 2.22-\mathrm{mm}, 3.45-\mathrm{mm}$ Early Treatment Diabetic Retinopathy Study grid on the fovea and averaging the thickness of all quadrants. GCIP thickness was the summation of the ganglion cell layer and inner plexiform layer. The software calculated the mean pRNFL 
thickness, $360^{\circ}$ around the $\mathrm{ONH}$. All ONH scans fulfilled the OSCAR-IB quality consensus criteria. ${ }^{22}$ All scans were reviewed by a single author (C.A.W.) and, when necessary, segmentation boundaries manually corrected. OCT data have been reported in line with the Advised Protocol for OCT Study Terminology and Elements recommendations (APOSTEL). ${ }^{23}$

\section{Statistics}

Statistical analyses were performed using $\mathrm{R}$ version 3.3.1 ( $\mathrm{R}$ Core Team, 2016; r-project.org). To assess whether time between symptom onset and baseline examination may influence the OCT analysis, an unpaired, 2-sample $t$ test was used to compare the mean baseline GCIP thickness of the ON eyes between early ( $\leq 7$ days) and late ( $>7$ days) presenting patients. All retinal layers derived from OCT measurements were analyzed independently of each other. For each layer, a linear mixed-effects model was used to assess the differences between ipsilateral $\mathrm{ON}$ eyes and contralateral non-ON (NON) eyes over time. The response variable of the model was the $\triangle \mathrm{GCIP}, \Delta \mathrm{pRNFL}$, or $\Delta \mathrm{INL}$ (the difference between the retinal layer thickness of an $\mathrm{ON}$ eye at each time point and the retinal layer thickness of the corresponding NON eye at baseline). All comparisons were made to the baseline of the NON eyes assuming that the baseline of the NON eyes is nonpathologic and therefore suitable as an intraindividual control. This approach is further supported by previous studies suggesting that analysis of intereye thickness differences is more accurate in detecting retinal ganglion cell (RGC) damage than absolute thicknesses ${ }^{24}$ and that withinpatients comparisons are more sensitive than comparisons to a healthy control group. ${ }^{25,26}$ All models included time points, age, sex, disease duration, steroid treatment (yes/no), and disease-modifying therapy (DMT) (yes/no) as fixed effects and a random effect accounted for intraindividual comparisons; furthermore, the model is known to efficiently handle missing values. ${ }^{27}$ The residuals of the model were tested for normality with the Shapiro-Wilk test and by inspection of the residuals and Q-Q plots. The relationship between GCIP thickness and LCVA in ON eyes was assessed by Spearman rank correlations. All $p$ values were Bonferroni corrected for multiple comparisons. $p$ Values $\leq 0.05$ were considered statistically significant.

\section{Data availability}

All data from this study will be available (in anonymized form) on reasonable request from any qualified investigator.

\section{Results}

\section{Patient demographics and clinical characteristics}

Patient demographics and clinical characteristics obtained at baseline clinical evaluation are detailed in table 1 . In total, 41 patients ( 28 women and 13 men; mean age: 32.4 years) were included in the study. Thirty patients (73.2\%) had an ON in the context of MS, whereas 11 cases $(26.8 \%)$ were diagnosed with
Table 1 Patient demographics and clinical characteristics at baseline examination

\begin{tabular}{llll}
\hline & Total & Female & Male \\
\hline No. of patients & 41 & 28 & 13 \\
\hline Mean age (SD) [y] & $32.4(9.4)$ & $32.0(10.8)$ & $33.3(5.4)$ \\
\hline Mean disease duration (SD) [d] & & & \\
\hline Median [d] & $184(730)$ & $207(873)$ & $134(234)$ \\
\hline Minimum [d] & 2 & 2 & 2 \\
\hline Maximum [d] & 4,611 & 4,611 & 804 \\
\hline
\end{tabular}

Cause of ON

\begin{tabular}{llll}
\hline Idiopathic ON & 11 & 8 & 3 \\
\hline CIS & 7 & 6 & 1 \\
\hline RRMS & 22 & 14 & 8 \\
\hline PPMS & 1 & 0 & 1 \\
\hline
\end{tabular}

ON presentation

\begin{tabular}{llll}
\hline Unilateral & 39 & 27 & 12 \\
\hline Bilateral & 2 & 1 & 1 \\
\hline $\begin{array}{l}\text { Mean time from clinical onset } \\
\text { of ON to baseline scan (SD) [d] }\end{array}$ & $10(7)$ & $11(8)$ & $8(4)$ \\
\hline $\begin{array}{l}\text { Patients treated with } \\
\text { corticosteroids }\end{array}$ & 37 & 25 & 12 \\
\hline Patients treated with DMT & 17 & 11 & 6 \\
\hline
\end{tabular}

Ethnicity

\begin{tabular}{llll}
\hline European & 38 & 27 & 11 \\
\hline South Asian & 1 & 0 & 1 \\
\hline West African & 1 & 0 & 1 \\
\hline North American & 1 & 1 & 0 \\
\hline
\end{tabular}

Abbreviations: $\mathrm{CIS}=$ clinically isolated syndrome; DMT = disease-modifying therapy; ON = optic neuritis; PPMS = primary progressive MS; RRMS = relapsing-remitting MS.

idiopathic ON. In cases with bilateral ON $(n=2)$, the more severely affected eye at baseline was classified as the ON eye. From the less severely affected eye, only baseline results were analyzed and used to calculate intereye differences over time, whereas the follow-up data were excluded. The mean time from clinical onset of $\mathrm{ON}$ to baseline examination was 10 days. The average GCIP thickness in ON eyes was not significantly different $(p=0.13)$ between patients presenting early or late for baseline examination. One patient had a clinical ON event during follow-up, affecting the contralateral eye at month 12; the data for this eye at month 12 were excluded from analysis.

\section{Structural retinal damage following ON}

GCIP thickness in NON eyes remained stable, whereas GCIP thickness in $\mathrm{ON}$ eyes decreased over time. The mean $\Delta$ GCIP differed significantly in ON eyes at all time points 
$(p<0.0001)$ post-ON (figure 1 , table 2$)$. ON eyes had a mean GCIP reduction over the 12-month follow-up period of $14.1 \mu \mathrm{m}$ (SD: $3.2 \mu \mathrm{m}$ ), with $74.5 \%$ of the change occurring within the first month and $100 \%$ within 3 months following ON (figure 1, table 2). Except for time points, none of the covariates (age, sex, disease duration, steroid treatment, and DMT) appeared to have a significant effect on the response variables ( $\Delta$ GCIP, $\Delta \mathrm{pRNFL}$, or $\Delta \mathrm{INL}$ ), but were nevertheless included in the statistical model, as preplanned. In comparison, the mean longitudinal GCIP thickness in NON eyes showed an absolute reduction of $1.1 \mu \mathrm{m}$ (SD: $2.2 \mu \mathrm{m}$ ) over the same period (table 3).

Although we observed numerical differences between men and women in terms of GCIP reduction after 12 months (men: $-19.8 \mu \mathrm{m}, \mathrm{SD}: 4.9 \mu \mathrm{m}$ vs women: $-10.3 \mu \mathrm{m}, \mathrm{SD}$ : $4.1 \mu \mathrm{m}$ ), these differences did not reach statistical significance (tables e-1 and e-2, links.lww.com/NXI/A187).

Mean baseline pRNFL thickness in ON eyes was $116.2 \mu \mathrm{m}$ (SD: $29.3 \mu \mathrm{m}$ ) and had an average thickness difference of $+18.2 \mu \mathrm{m}$ (SD: $4.8 \mu \mathrm{m})$ compared with contralateral NON eyes (table 2 , figure 1 ). The mean $\Delta$ pRNFL was significantly different at months $1(p<0.05), 3(p<0.0001), 6(p<$ $0.0001)$, and $12(p<0.0001)$ post-ON. Although most of the total pRNFL reduction $(87.8 \%)$ occurred within the first 3 months post-ON, thickness continued to slowly decline up until month 12 (table 1). In NON eyes, mean pRNFL thickness values between $96.0 \mu \mathrm{m}$ and $99.0 \mu \mathrm{m}$ were reported over the 12-month period (table 3). At baseline, women had a mean pRNFL thickness of $113.9 \mu \mathrm{m}$ (SD: $31.3 \mu \mathrm{m})$ in ON eyes and a difference of $+15.79 \mu \mathrm{m}$ (SD: $6.1 \mu \mathrm{m})$ compared with their respective NON eyes, whereas the ON eyes in men had a mean pRNFL thickness of $121.0 \mu \mathrm{m}$ (SD: $24.9 \mu \mathrm{m}$ ) and a difference of $+23.4 \mu \mathrm{m}$ (SD: $7.4 \mu \mathrm{m})$ compared with the respective NON eyes. By month 6 , women and men had almost identical mean pRNFL thicknesses. Subsequent to month 6, pRNFL thickness stabilized until month 12 in women, whereas men experienced a further decline (tables e-1 and e-2, links.lww.com/NXI/A187).

The baseline mean INL thickness was similar in NON and ON eyes (table 2, figure 1). However, a significant intereye difference between month 1 macular INL thickness in ON eyes and baseline contralateral INL thickness $(p<0.05)$ was found (figure 1).

The INL thickness in ON eyes showed more pronounced changes over time in men than in women. At month 1 following ON, mean INL thickness was similar in men and women. In female ON eyes, mean INL thickness remained nearly unchanged up to month 12 , whereas in male $\mathrm{ON}$ eyes, mean INL thickness increased by $3.0 \mu \mathrm{m}$ (SD: $1.6 \mu \mathrm{m})$ at month 12 (tables e-1 and e-2, links.lww.com/NXI/A187).

In NON eyes, almost no change in mean INL thickness was observed at months 1,3 , and 6 , but there was a significant increase at month $12(+1.4 \mu \mathrm{m}, \mathrm{SD}: 1.1 \mu \mathrm{m}, p<0.05)$ compared with baseline (table 3 ). Although small in magnitude, this increase nevertheless represents a change of $+3.9 \%$ by month 12 compared with the baseline examination.

\section{Visual functional changes following ON}

Visual acuity of $\mathrm{ON}$ eyes was lowest at the acute phase of $\mathrm{ON}$ and was worse compared with that of NON eyes (figure 2, table e-3, links.lww.com/NXI/A187). Subsequently, visual acuity recovered partially; although HCVA improved rapidly in $\mathrm{ON}$ eyes and was comparable to measurements in the NON eyes already at month 3, LCVA never reached the level of NON eyes during the entire observation period (figure 2). Namely, ON eyes displayed a mean LCVA intereye difference of $0.23 \log \mathrm{MAR}$, corresponding to 11-12 letters at month 12 .

\section{Association between macular damage and visual outcomes}

Thinner GCIP thickness at month 1 was correlated with lower LCVA at month 3 (rho $=-0.63, p=0.01)$ in ON eyes. No statistically significant relationship was found between GCIP thickness and LCVA at month 6 or 12. Furthermore, no associations were observed between GCIP thickness at month 1 and HCVA at any time point.

\section{Discussion}

We found that an episode of acute ON can result in extensive neuroaxonal retinal damage of the ipsilateral eye, confirming previous longitudinal reports. ${ }^{17,18}$ Significant GCIP thinning was already detectable at 1 month after $\mathrm{ON}$ and also at all subsequent time points.

The status of the retina distal to GCIP beyond 6 months post-ON has previously not been documented. We measured a small but significant increase in INL thickness in the clinically (seemingly) unaffected NON eyes at month 12 , suggestive of bilateral retinal pathology in clinically unilateral ON.

Similarly, a significant intereye difference between month 1 INL thickness in ON eyes and baseline contralateral INL thickness was observed. Although the detected changes are numerically small, the INL thickness increase in the ON eyes recorded was similar in magnitude to previous findings, including a large meta-analysis. ${ }^{12}$ All these previously reported changes to INL thickness, including the current findings, are below the axial resolution of the OCT device used in this study $(\sim 5 \mu \mathrm{m})$; however, several studies have recorded that the detection limit for retinal layer thickness changes is approximately $1 \mu \mathrm{m} .{ }^{28,29}$ Thus, it is likely that the observed INL thickening is meaningful. Nevertheless, it may be prudent to be cautious when interpreting such findings at the individual patient level. Recently, it has been suggested that the INL shows promise as a possible marker of MS inflammatory disease activity and response to treatment, with INL 
Figure 1 Longitudinal retinal thickness in ON

A

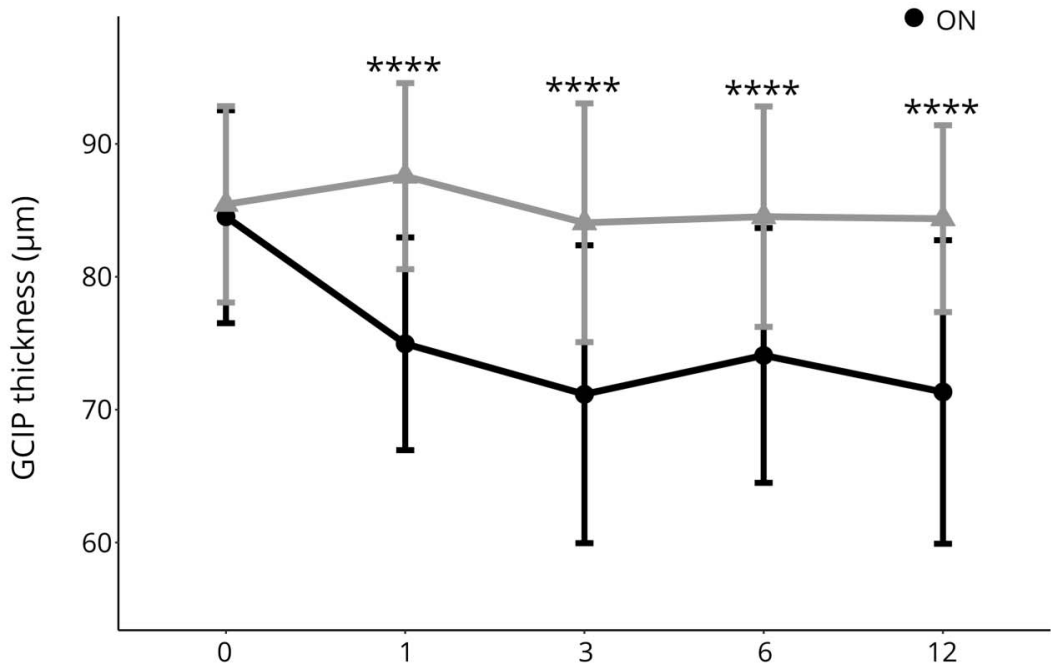

B

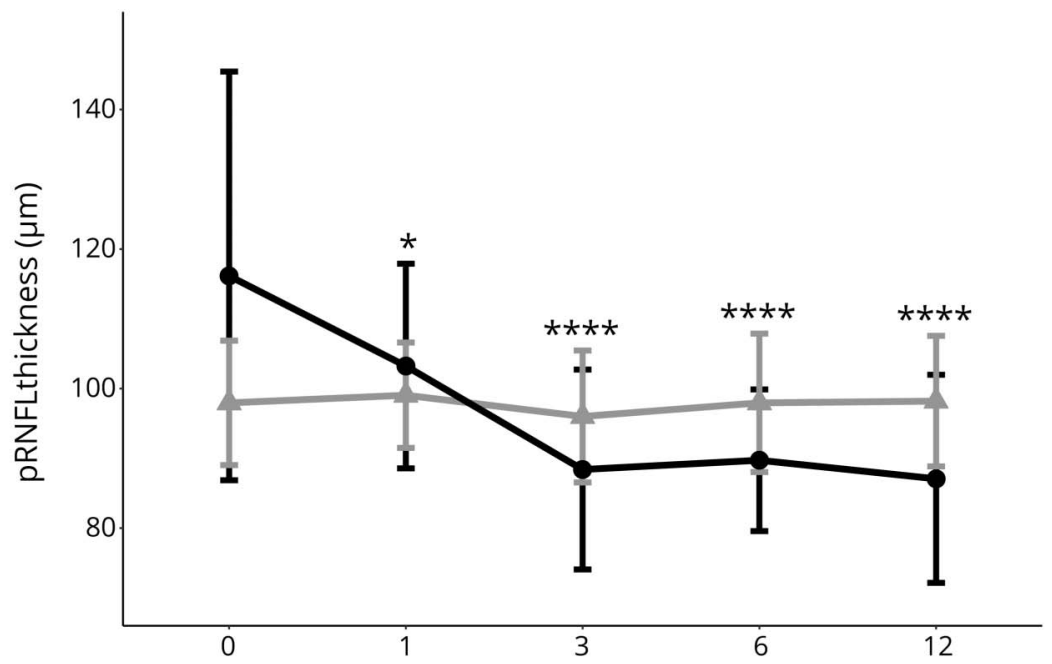

C

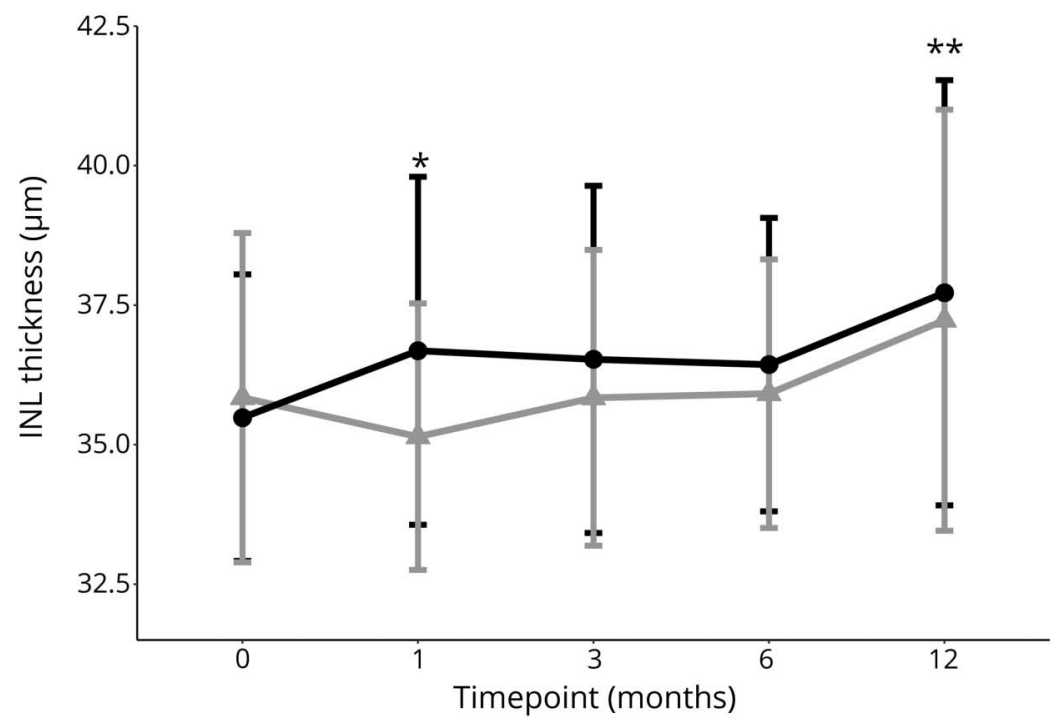

A) Reduction in mean macular GCIP thickness in ON eyes at baseline and in the subsequent 12 months compared with baseline mean GCIP thickness in NON eyes ( $* * \star * p<0.0001)$. (B) Mean pRNFL thickness in NON and $\mathrm{ON}$ eyes at baseline and in the subsequent 12

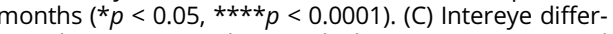
ence between macular INL thickness in ON eyes and baseline contralateral INL thickness $\left({ }^{*} p<0.05\right)$. Intraeye difference in macular INL thickness in NON eyes over time $\left({ }^{*} p<0.05\right)$. Error bars represent SDs. GCIP = ganglion cell and inner plexiform layer; INL = inner nuclear layer; $\mathrm{NON}$ = nonoptic neuritis; $\mathrm{ON}$ = optic neuritis; pRNFL = peripapillary retinal nerve fiber layer. 
Table 2 Retinal thickness in NON eyes at baseline and in ON eyes over a 12-month period

\begin{tabular}{|c|c|c|c|c|c|c|}
\hline & \multirow{2}{*}{$\frac{\text { NON }}{\text { Mo }}$} & \multicolumn{5}{|l|}{ ON } \\
\hline & & MO & M1 & M3 & M6 & M12 \\
\hline \multicolumn{7}{|l|}{ Macular GCIP } \\
\hline Mean $(\mathrm{SD})[\mu \mathrm{m}]$ & $85.0(7.4)$ & $84.0(8.0)$ & $74.5(8.0)$ & $70.7(11.2)$ & $73.6(9.6)$ & $70.8(11.4)$ \\
\hline Absolute change (SD) $[\mu \mathrm{m}]$ & NA & $-0.9(1.8)$ & $-10.5(2.1)$ & $-14.3(2.5)$ & $-11.4(2.4)$ & $-14.1(3.2)$ \\
\hline No. of eyes & 40 & 36 & 21 & 25 & 22 & 15 \\
\hline \multicolumn{7}{|l|}{ pRNFL } \\
\hline Mean $(\mathrm{SD})[\mu \mathrm{m}]$ & $98.0(8.9)$ & $116.2(29.3)$ & $103.2(14.7)$ & $88.4(14.3)$ & $89.7(10.2)$ & $87.1(14.9)$ \\
\hline Absolute change (SD) $[\mu \mathrm{m}]$ & NA & $18.2(4.8)$ & $5.3(3.4)$ & $-9.6(3.2)$ & $-8.2(2.6)$ & $-10.9(4.1)$ \\
\hline No. of eyes & 41 & 41 & 22 & 25 & 22 & 15 \\
\hline \multicolumn{7}{|l|}{ Macular INL } \\
\hline Mean (SD) $[\mu \mathrm{m}]$ & $35.8(2.9)$ & $35.5(2.6)$ & $36.7(3.1)$ & $36.5(3.1)$ & $36.4(2.6)$ & $37.7(3.8)$ \\
\hline Absolute change (SD) $[\mu \mathrm{m}]$ & NA & $-0.4(0.6)$ & $0.8(0.8)$ & $0.7(0.8)$ & $0.6(0.7)$ & $1.9(1.1)$ \\
\hline No. of eyes & 40 & 36 & 21 & 25 & 22 & 15 \\
\hline
\end{tabular}

Abbreviations: $\mathrm{GCIP}=$ ganglion cell and inner plexiform layer; $\mathrm{INL}=$ inner nuclear layer; $\mathrm{M} 0=$ month $0 ; \mathrm{M} 1=$ month $1 ; \mathrm{M} 3=$ month $3 ; \mathrm{M} 6=\mathrm{month} 6 ; \mathrm{M} 12=$ month 12; NA = not applicable; NON = nonoptic neuritis eye; ON = optic neuritis, pRNFL = peripapillary retinal nerve fiber layer.

thickening being associated with more active or breakthrough disease. $^{7,29-31}$ Therefore, INL thickening in ON eyes may be due to mechanisms related to inflammation within or affecting the INL. ${ }^{7,29,30}$ Increased INL thickness has also been associated with the presence of microcystic macular edema (MME), particularly in patients with a history of MS-related ON or neuromyelitis optica spectrum disorders (NMOSDs). ${ }^{31,32}$ In our cohort, signs of MME were only observed in 1 patient, in whom only pRNFL data were analyzed. Moreover, none of the 11 idiopathic ON cases could be confirmed as $\mathrm{NMOSD}^{33}$ ( 8 were seronegative for aquaporin-4 antibodies [AQP4-IgG], whereas the other 3 were untested). Neither MME nor NMOSD appears to explain the mean INL increase we detected.

Table 3 Retinal thickness in NON eyes over a 12-month period

\begin{tabular}{|c|c|c|c|c|c|}
\hline & Mo & M1 & M3 & M6 & M12 \\
\hline \multicolumn{6}{|l|}{ Macular GCIP } \\
\hline Mean $(\mathrm{SD})[\mu \mathrm{m}]$ & $85.0(7.4)$ & $87.1(7.0)$ & $83.6(9.0)$ & $84.0(8.3)$ & $83.9(7.0)$ \\
\hline Absolute change (SD) $[\mu \mathrm{m}]$ & NA & $2.1(1.9)$ & $-1.4(2.1)$ & $-0.9(2.1)$ & $-1.1(2.2)$ \\
\hline No. of scans & 40 & 21 & 24 & 21 & 15 \\
\hline \multicolumn{6}{|l|}{ pRNFL } \\
\hline Mean (SD) $[\mu \mathrm{m}]$ & $98.0(8.9)$ & $99.0(7.6)$ & $96.0(9.5)$ & $98.0(9.9)$ & $98.2(9.4)$ \\
\hline Absolute change (SD) $[\mu \mathrm{m}]$ & NA & $1.1(2.1)$ & $-2.0(2.4)$ & $0.0(2.5)$ & $0.2(2.8)$ \\
\hline No. of scans & 41 & 21 & 24 & 21 & 15 \\
\hline \multicolumn{6}{|l|}{ Macular INL } \\
\hline Mean $(\mathrm{SD})[\mu \mathrm{m}]$ & $35.8(2.9)$ & $35.1(2.4)$ & $36.0(2.6)$ & $35.9(2.4)$ & $37.2(3.8)$ \\
\hline Absolute change (SD) $[\mu \mathrm{m}]$ & NA & $-0.7(0.7)$ & $-0.2(0.7)$ & $0.1(0.7)$ & $1.4(1.1)$ \\
\hline No. of scans & 40 & 21 & 24 & 21 & 15 \\
\hline
\end{tabular}

Abbreviations: GCIP = ganglion cell and inner plexiform layer; $\mathrm{INL}=$ inner nuclear layer; $\mathrm{M} 0=$ month $0 ; \mathrm{M} 1=$ month $1 ; \mathrm{M} 3=$ month 3; $\mathrm{M} 6=$ month 6 ; $\mathrm{M} 12=$ month 12; NA = not applicable; NON = nonoptic neuritis eye; $\mathrm{PRNFL}$ = peripapillary retinal nerve fiber layer. 

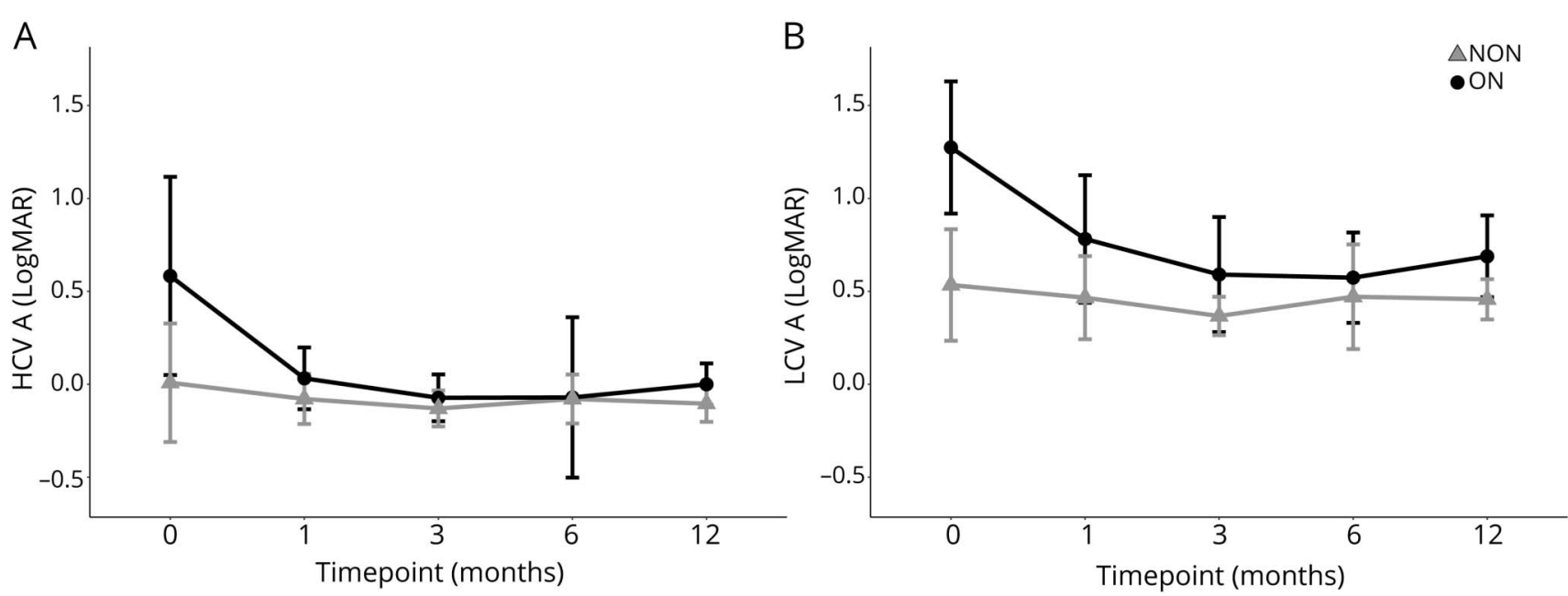

Best-corrected mean HCVA (A) and LCVA (B) measures in ON eyes and NON eyes over a 12-month period. Error bars represent SDs. HCVA = high-contrast visual acuity; LCVA = low-contrast visual acuity; logMAR = logarithm of the minimum angle of resolution; NON = nonoptic neuritis; ON = optic neuritis.

The change in INL thickness in the NON eyes may indicate subclinical involvement of the fellow eyes in our patients with ON. Although this structural finding is novel in the literature, we may draw parallels with 2 results from functional studies and data from a clinical trial in ON. Schnurman et al. ${ }^{15}$ showed abnormalities of the ONH component of the multifocal electroretinogram in $\mathrm{ON}$ eyes but also, to a lesser extent, in the NON eyes of the same patients. In a substudy of a recent clinical trial assessing the monoclonal anti-LINGO-1 antibody opicinumab in acute $\mathrm{ON}$, fellow eyes of placebotreated, but not opicinumab-treated, patients showed progressive multifocal visual evoked potential (VEP) amplitude loss over 8 months. ${ }^{34}$ Similarly, Raz et al. ${ }^{16}$ found changes to the latency of late peaks of the VEP of NON eyes, which were not attributable to demyelination; the authors attributed these changes to an adaptive mechanism to maximize preservation of stereopsis in their patients with unilateral ON. We are unable to reach firm conclusions as to the etiology of our INL thickness changes, but we suggest subclinical inflammation of the fellow eye as a potential candidate. Alternatively, given the proposed role of the INL as a marker for global inflammatory disease activity in MS, the increased INL thickness in NON eyes at month 12 may be indicative of ongoing or future disease activity independent of ON. However, the fact that Balk et al. ${ }^{35}$ did not observe a significant annualized change in INL volume in MS eyes without a recent history of ON may argue against this hypothesis.

By month 12, the magnitude of macular GCIP thinning was $-16.6 \%$ in $\mathrm{ON}$ eyes relative to the baseline of contralateral NON eyes. An important finding of our study is the extremely rapid evolution of macular GCIP atrophy in affected eyes, with nearly $75 \%$ of the entire reduction observed over 12 months occurring within the first month of presentation and $100 \%$ occurring by month 3 . Gabilondo et al. ${ }^{17}$ described comparable temporal dynamics of GCIP atrophy subsequent to ON, reporting $57.2 \%$ of the total reduction in thickness occurring within the first 2 months and $73.4 \%$ within the first 3 months. Our results have important implications for future interventions and clinical trial design: as the magnitude of change is most pronounced early in the course of $\mathrm{ON}$, very early, if not prophylactic intervention, may be the best strategy to prevent tissue damage in acute ON. Moreover, sample size calculations for future clinical trials may be based on the data presented here. Notably, NON eyes had some level of RGC degeneration above thresholds of physiologic aging, ${ }^{36}$ consistent with a recent report on longitudinal retinal changes in NON eyes among patients with MS and again suggesting subclinical involvement of the contralateral eye in ON. ${ }^{17}$

pRNFL thickness of ON eyes was increased at baseline examination, most likely indicative of inflammatory edema. At month 1 , peripapillary thickening was still evident but had reduced substantially. Subsequently, pRNFL reduced in thickness, reaching most of its total reduction (87.8\%) by month 3 and showing a moderately sustained decline until month 12 , in line with previous studies. ${ }^{18,37}$

To ensure that our data regarding the temporal course of GCIP, pRNFL, and INL thickness changes are not artifactual (due to assessing different patients at different time points), we performed a subanalysis of patients who had both baseline and month 12 examinations. The results of this subanalysis confirmed GCIP and pRNFL thinning, as well as INL thickening, 1 year after ON (data not shown).

Treatment with corticosteroids (mean time between onset of ON and administration: 10 days) was included as a dichotomous variable in the statistical model and was found to have no significant influence on the OCT measures assessed. 
In NMOSD, the effect of steroids on visual outcomes appears to depend critically on the timing of application, with an optimal effect being achieved with administration $\leq 4$ days after onset. ${ }^{38}$ Yet, in MS-associated ON, both timing and overall impact of steroid treatment have not been shown conclusively. Future studies may consider including temporal information on steroid treatment as a continuous variable in the statistical models.

A profound reduction in HCVA and LCVA was observed in $\mathrm{ON}$ eyes at baseline. Although HCVA recovered rapidly in the majority of patients, with the mean reaching the level of the unaffected eye at month 6, LCVA remained impaired for the entire study period, with a clinically relevant ${ }^{9}$ intereye difference of 11-12 letters.

We also addressed a putative link between early changes to macular architecture after $\mathrm{ON}$ and subsequent visual functional loss. LCVA at month 3 tended to be worse in ON eyes with GCIP thinning at month 1 . The lack of a significant association between early GCIP thickness and LCVA at months 6 or 12 may be due to diminished statistical power with smaller sample sizes at these time points. No correlation was found between early GCIP thickness and HCVA at any time point during follow-up, which is unsurprising, given the functional improvement in HCVA up to the level of the contralateral eye at month 6. Together, these results illustrate the importance of LCVA monitoring to properly identify functional visual recovery in MS-associated ON.

An exploratory objective of the study was to analyze sexspecific differences in the outcome of acute ON episodes. Female preponderance is well known in MS. However, previous studies have reported that once the disease manifests, men are more severely affected than women, characterized by a more rapid disease progression and worsening of clinical outcomes. $^{39}$ To date, few studies have looked into potential influences of sex effects on visual outcomes in ON. ${ }^{18,40}$ Those studies that have analyzed the effects of sex on recovery after ON have suggested poorer outcomes in men. ${ }^{18,40}$ Although our raw data were consistent with these previous findings (men demonstrated greater structural changes in GCIP, pRNFL, and INL thickness compared with women), our analyses did not reveal statistically significant effects of sex. This may be due to the low number of males included in our study $(\mathrm{n}=13)$. As previous work did not state explicitly whether results were corrected for multiple testing, ${ }^{18,40}$ it remains possible that our negative findings regarding sex also reflect differences in statistical analysis methods.

Our study has a number of limitations. As a consequence of its retrospective nature, data were not available for all patients at each follow-up time point, resulting in a smaller sample size at follow-ups compared with baseline and also in a slightly different cohort at each time point. In addition, the study lacked a dedicated healthy control group. Although all comparisons were made to the baseline of the NON eyes based on the assumption that the baseline of the NON eyes is nonpathologic, it cannot be completely ruled out that NON eyes previously experienced retinal pathology following subclinical $\mathrm{ON}$. The latter also holds true for the $\mathrm{ON}$ eyes.

The characterization of temporal dynamics underlying neuroaxonal damage in $\mathrm{ON}$ and factors associated with a poor functional outcome is important for optimizing timing, patient selection, and mechanisms to target in future interventions. Thus, future prospective studies in $\mathrm{ON}$ including the contralateral eyes are needed to confirm the findings reported here in larger cohorts. Such studies may also add clinical relapse rate or radiologic disease activity as outcomes to better assess the clinical significance of the OCT findings reported and to further improve our understanding of the basic mechanisms underlying tissue damage in ON. Such results may pave the way for targeted interventions with the aim of reducing functional visual sequelae.

Overall, our results indicate that macular structural damage develops rapidly in patients with acute $\mathrm{ON}$ in affected eyes and correlates with functional visual outcomes. LCVA recovery is incomplete following an episode of acute $\mathrm{ON}$. We also provide preliminary evidence for structural pathology involving the contralateral, clinically unaffected eyes, which may be explained by subclinical involvement of the fellow eye in ON. Our results further strengthen the importance of early intervention when planning for clinical trials targeting tissue protection in acute $\mathrm{ON}$.

\section{Acknowledgment}

The authors thank all their patients who participated in this study. They also thank Sebastian C. Lukas and Elisabeth D. Olbert for assisting in the collection of data. This work has been previously presented at European Committee for Treatment and Research in Multiple Sclerosis and awarded a Poster Prize (ECTRIMS 2017, Paris, FR).

\section{Study funding}

This study was supported by the Swiss National Science Foundation (320030_175770). None of the funding sources had any role in designing the study, in collection, analysis, or interpretation of data, or in writing the manuscript.

\section{Disclosure}

C.A. Wicki has received travel grants from Teva and Merck Serono. P. Manogaran has received travel grants from Merck Serono and Sanofi Genzyme. T. Simic reports no disclosures. J.V.M. Hanson is supported by the Clinical Research Priority Program of the University of Zurich. S. Schippling is supported by the Swiss National Science Foundation (320030_175770), the Myelin Repair Foundation, the Clinical Research Priority Program of the University of Zurich, and the Swiss MS Society and has received research grants from Novartis and Sanofi Genzyme and consultancy and speaking fees from Biogen, Merck Serono, Novartis, Roche, Sanofi Genzyme, and Teva. Go to Neurology.org/NN for full disclosures. 


\section{Publication history}

Received by Neurology: Neuroimmunology \& Neuroinflammation July 19, 2019. Accepted in final form December 16, 2019.

Appendix Authors

\begin{tabular}{|c|c|c|c|}
\hline Name & Affiliation & Role & Contribution \\
\hline $\begin{array}{l}\text { Carla A. } \\
\text { Wicki, MSc }\end{array}$ & $\begin{array}{l}\text { Department of } \\
\text { Health Sciences and } \\
\text { Technology, Swiss } \\
\text { Federal Institute of } \\
\text { Technology, Zurich, } \\
\text { Switzerland; } \\
\text { Neuroimmunology } \\
\text { and Multiple Sclerosis } \\
\text { Research, } \\
\text { Department of } \\
\text { Neurology, University } \\
\text { Hospital Zurich and } \\
\text { University of Zurich, } \\
\text { Switzerland; wickic@ } \\
\text { student.ethz.ch }\end{array}$ & Author & $\begin{array}{l}\text { Collected, analyzed, } \\
\text { and interpreted the } \\
\text { data and wrote the } \\
\text { manuscript and } \\
\text { critically revised it }\end{array}$ \\
\hline $\begin{array}{l}\text { Praveena } \\
\text { Manogaran, } \\
\text { MSc }\end{array}$ & $\begin{array}{l}\text { Department of } \\
\text { Information } \\
\text { Technology and } \\
\text { Electrical } \\
\text { Engineering, Swiss } \\
\text { Federal Institute of } \\
\text { Technology, Zurich, } \\
\text { Switzerland; } \\
\text { Neuroimmunology } \\
\text { and Multiple Sclerosis } \\
\text { Research, } \\
\text { Department of } \\
\text { Neurology, University } \\
\text { Hospital Zurich and } \\
\text { University of Zurich, } \\
\text { Switzerland; } \\
\text { pmanogar@ } \\
\text { student.ethz.ch }\end{array}$ & Author & $\begin{array}{l}\text { Collected and } \\
\text { analyzed the data } \\
\text { and revised the } \\
\text { manuscript }\end{array}$ \\
\hline
\end{tabular}

\begin{tabular}{|c|c|c|c|}
\hline $\begin{array}{l}\text { Tanja Simic, } \\
\text { RN }\end{array}$ & $\begin{array}{l}\text { Neuroimmunology } \\
\text { and Multiple Sclerosis } \\
\text { Research, } \\
\text { Department of } \\
\text { Neurology, University } \\
\text { Hospital Zurich and } \\
\text { University of Zurich, } \\
\text { Switzerland; } \\
\text { Tanja.Simic@usz.ch }\end{array}$ & Author & $\begin{array}{l}\text { Major role in the } \\
\text { acquisition of data }\end{array}$ \\
\hline $\begin{array}{l}\text { James V.M. } \\
\text { Hanson, } \\
\text { PhD }\end{array}$ & $\begin{array}{l}\text { Neuroimmunology } \\
\text { and Multiple Sclerosis } \\
\text { Research, Department } \\
\text { of Neurology, } \\
\text { University Hospital } \\
\text { Zurich and University } \\
\text { of Zurich, Switzerland; } \\
\text { Department of } \\
\text { Ophthalmology, } \\
\text { University Hospital } \\
\text { Zurich and University } \\
\text { of Zurich, Switzerland; } \\
\text { James.Hanson@ } \\
\text { usz.ch }\end{array}$ & Author & $\begin{array}{l}\text { Collected and } \\
\text { interpreted the data } \\
\text { and critically revised } \\
\text { the manuscript for } \\
\text { intellectual content }\end{array}$ \\
\hline $\begin{array}{l}\text { Sven } \\
\text { Schippling, } \\
\text { MD }\end{array}$ & $\begin{array}{l}\text { Neuroimmunology } \\
\text { and Multiple Sclerosis } \\
\text { Research, } \\
\text { Department of } \\
\text { Neurology, University } \\
\text { Hospital Zurich and } \\
\text { University of Zurich, } \\
\text { Switzerland; } \\
\text { Sven.Schippling@ } \\
\text { usz.ch }\end{array}$ & Author & $\begin{array}{l}\text { Designed and } \\
\text { conceptualized the } \\
\text { study and critically } \\
\text { revised the } \\
\text { manuscript for } \\
\text { intellectual content }\end{array}$ \\
\hline
\end{tabular}

\section{References}

1. Luessi F, Siffrin V, Zipp F. Neurodegeneration in multiple sclerosis: novel treatment strategies. Expert Rev Neurother 2012;12:1061-1076; quiz 1077.

2. Miller D, Barkhof F, Montalban X, Thompson A, Filippi M. Clinically isolated syndromes suggestive of multiple sclerosis, part I: natural history, pathogenesis, diagnosis, and prognosis. Lancet Neurol 2005;4:281-288.

3. Toosy AT, Mason DF, Miller DH. Optic neuritis. Lancet Neurol 2014;13:83-99.

4. Syc SB, Saidha S, Newsome SD, et al. Optical coherence tomography segmentation reveals ganglion cell layer pathology after optic neuritis. Brain 2012;135: 521-533.

5. Frohman EM, Fujimoto JG, Frohman TC, Calabresi PA, Cutter G, Balcer LJ. Optical coherence tomography: a window into the mechanisms of multiple sclerosis. Nat Clin Pract Neurol 2008;4:664-675.

6. Costello F, Coupland S, Hodge W, et al. Quantifying axonal loss after optic neuritis with optical coherence tomography. Ann Neurol 2006;59:963-969.

7. Green AJ, McQuaid S, Hauser SL, Allen IV, Lyness R. Ocular pathology in multiple sclerosis: retinal atrophy and inflammation irrespective of disease duration. Brain 2010;133:1591-1601.

8. Walter SD, Ishikawa H, Galetta KM, et al. Ganglion cell loss in relation to visual disability in multiple sclerosis. Ophthalmology 2012;119:1250-1257.

9. Balcer LJ, Raynowska J, Nolan R, et al. Validity of low-contrast letter acuity as a visual performance outcome measure for multiple sclerosis. Mult Scler 2017;23:734-747.

10. Martinez-Lapiscina EH, Arnow S, Wilson JA, et al. Retinal thickness measured with optical coherence tomography and risk of disability worsening in multiple sclerosis: a cohort study. Lancet Neurol 2016;15:574-584.

11. Al-Louzi OA, Bhargava $\mathrm{P}, \mathrm{Newsome} \mathrm{SD}$, et al. Outer retinal changes following acute optic neuritis. Mult Scler 2016;22:362-372.

12. Petzold A, Balcer LJ, Calabresi PA, et al. Retinal layer segmentation in multiple sclerosis: a systematic review and meta-analysis. Lancet Neurol 2017;16:797-812.

13. Hanson JVM, Hediger M, Manogaran P, et al. Outer retinal dysfunction in the absence of structural abnormalities in multiple sclerosis. Invest Ophthalmol Vis Sci 2018;59:549-560.

14. Klistorner A, Arvind H, Nguyen T, et al. Fellow eye changes in optic neuritis correlate with the risk of multiple sclerosis. Mult Scler 2009;15:928-932.

15. Schnurman ZS, Frohman TC, Beh SC, et al. Retinal architecture and mfERG: optic nerve head component response characteristics in MS. Neurology 2014;82: 1888-1896.

16. Raz N, Chokron S, Ben-Hur T, Levin N. Temporal reorganization to overcome monocular demyelination. Neurology 2013;81:702-709.

17. Gabilondo I, Martínez-Lapiscina EH, Fraga-Pumar E, et al. Dynamics of retinal injury after acute optic neuritis. Ann Neurol 2015;77:517-528.

18. Costello F, Pan YI, Yeh EA, Hodge W, Burton JM, Kardon R. The temporal evolution of structural and functional measures after acute optic neuritis. J Neurol Neurosurg Psychiatry 2015;86:1369-1373.

19. Balk LJ, Twisk JW, Steenwijk MD, et al. A dam for retrograde axonal degeneration in multiple sclerosis?. J Neurol Neurosurg Psychiatry 2014;85:782-789.

20. Polman $\mathrm{CH}$, Reingold SC, Banwell B, et al. Diagnostic criteria for multiple sclerosis: 2010 revisions to the McDonald criteria. Ann Neurol 2011;69:292-302.

21. Ferris FL III, Kassoff A, Bresnick GH, Bailey I. New visual acuity charts for clinical research. Am J Ophthalmol 1982;94:91-96.

22. Schippling S, Balk LJ, Costello F, et al. Quality control for retinal OCT in multiple sclerosis: validation of the OSCAR-IB criteria. Mult Scler 2015;21:163-170.

23. Cruz-Herranz A, Balk LJ, Oberwahrenbrock T, et al. The APOSTEL recommendations for reporting quantitative optical coherence tomography studies. Neurology 2016;86:2303-2309.

24. Brandt AU, Specovius S, Oberwahrenbrock T, Zimmermann HG, Paul F, Costello F. Frequent retinal ganglion cell damage after acute optic neuritis. Mult Scler Relat Disord 2018;22:141-147.

25. Kupersmith MJ, Mandel G, Anderson S, Meltzer DE, Kardon R. Baseline, one and three month changes in the peripapillary retinal nerve fiber layer in acute optic neuritis: relation to baseline vision and MRI. J Neurol Sci 2011;308:117-123.

26. Kupersmith MJ, Anderson S, Kardon R. Predictive value of 1 month retinal nerve fiber layer thinning for deficits at 6 months after acute optic neuritis. Mult Scler 2013;19: 1743-1748.

27. Ibrahim JG, Molenberghs G. Missing data methods in longitudinal studies: a review. Test (Madr) 2009;18:1-43.

28. Oberwahrenbrock T, Weinhold M, Mikolajczak J, et al. Reliability of intra-retinal layer thickness estimates. PLoS One 2015;10:e0137316.

29. Knier B, Schmidt P, Aly L, et al. Retinal inner nuclear layer volume reflects response to immunotherapy in multiple sclerosis. Brain 2016;139:2855-2863.

30. Gelfand JM, Nolan R, Schwartz DM, Graves J, Green AJ. Microcystic macular oedema in multiple sclerosis is associated with disease severity. Brain 2012;135: 1786-1793.

31. Saidha S, Sotirchos ES, Ibrahim MA, et al. Microcystic macular oedema, thickness of the inner nuclear layer of the retina, and disease characteristics in multiple sclerosis: a retrospective study. Lancet Neurol 2012;11:963-972.

32. Gelfand JM, Cree BA, Nolan R, Arnow S, Green AJ. Microcystic inner nuclear layer abnormalities and neuromyelitis optica. JAMA Neurol 2013;70:629-633.

33. Wingerchuk DM, Banwell B, Bennett JL, et al. International consensus diagnostic criteria for neuromyelitis optica spectrum disorders. Neurology 2015;85: 177-189.

34. Klistorner A, Chai Y, Leocani L, et al. Assessment of opicinumab in acute optic neuritis using multifocal visual evoked potential. CNS Drugs 2018;32:1159-1171. 
35. Balk LJ, Coric D, Knier B, et al. Retinal inner nuclear layer volume reflects inflammatory disease activity in multiple sclerosis: a longitudinal OCT study. Mult Scler J Exp Transl Clin 2019;5:2055217319871582.

36. Balk LJ, Cruz-Herranz A, Albrecht P, et al. Timing of retinal neuronal and axonal loss in MS: a longitudinal OCT study. J Neurol 2016;263:1323-1331.

37. Henderson AP, Altmann DR, Trip AS, et al. A serial study of retinal changes following optic neuritis with sample size estimates for acute neuroprotection trials. Brain 2010; 133:2592-2602.
38. Stiebel-Kalish H, Hellmann MA, Mimouni M, et al. Does time equal vision in the acute treatment of a cohort of AQP4 and MOG optic neuritis? Neurol Neuroimmunol Neuroinflamm 2019;6:e572. doi: 10.1212/NXI.0000000000000572.

39. Koch $M$, Kingwell E, Rieckmann $P$, Tremlett $H$. The natural history of secondary progressive multiple sclerosis. J Neurol Neurosurg Psychiatry 2010;81: 1039-1043.

40. Costello F, Hodge W, Pan YI, et al. Sex-specific differences in retinal nerve fiber layer thinning after acute optic neuritis. Neurology 2012;79:1866-1872. 


\title{
Neurology \\ Neuroimmunology \& Neuroinflammation
}

\author{
Bilateral retinal pathology following a first-ever clinical episode of autoimmune optic \\ neuritis \\ Carla A. Wicki, Praveena Manogaran, Tanja Simic, et al. \\ Neurol Neuroimmunol Neuroinflamm 2020;7; \\ DOI 10.1212/NXI.0000000000000671
}

This information is current as of January 22, 2020

Updated Information \&

Services

References

Subspecialty Collections

Permissions \& Licensing

Reprints including high resolution figures, can be found at:

http://nn.neurology.org/content/7/2/e671.full.html

This article cites 40 articles, 4 of which you can access for free at: http://nn.neurology.org/content/7/2/e671.full.html\#\#ref-list-1

This article, along with others on similar topics, appears in the following collection(s):

Multiple sclerosis

http://nn.neurology.org//cgi/collection/multiple_sclerosis

Optic neuritis; see Neuro-ophthalmology/Optic Nerve

http://nn.neurology.org//cgi/collection/optic_neuritis

Retina

http://nn.neurology.org//cgi/collection/retina

Visual loss

http://nn.neurology.org//cgi/collection/visual_loss

Information about reproducing this article in parts (figures,tables) or in its entirety can be found online at:

http://nn.neurology.org/misc/about.xhtml\#permissions

Information about ordering reprints can be found online:

http://nn.neurology.org/misc/addir.xhtml\#reprintsus

Neurol Neuroimmunol Neuroinflamm is an official journal of the American Academy of Neurology.

Published since April 2014, it is an open-access, online-only, continuous publication journal. Copyright

Copyright (C) 2020 The Author(s). Published by Wolters Kluwer Health, Inc. on behalf of the American

Academy of Neurology.. All rights reserved. Online ISSN: 2332-7812.

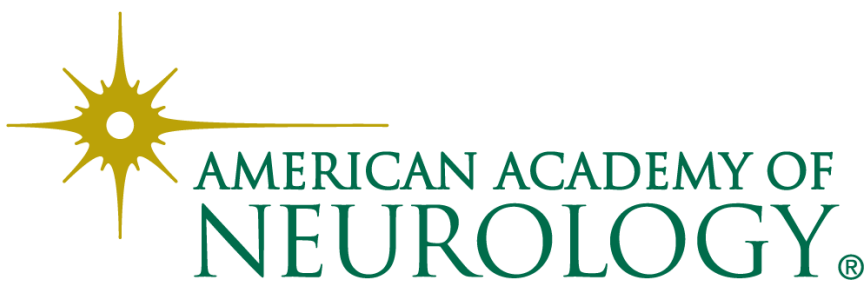

